\title{
The effect of training on the management of nuclear disasters by emergency department nurses and physicians
}

\author{
Alireza Ala', Farzad Rahmani ${ }^{*}$, Reza Aslzad', Zahra Parsian' \\ 'Emergency Medicine Research Team, Tabriz University of Medical Sciences, Tabriz, Iran
}

\author{
Received: 20 February 2017 \\ Accepted: 25 May 2017 \\ Published online: 1 June 2017 \\ *Corresponding author: Farzad \\ Rahmani, Emergency Medicine \\ Department, Imam Reza Hospital, \\ Tabriz University of Medical \\ Sciences, Golgasht Avenue, Tabriz \\ Iran. \\ Fax: 00984113352078; \\ Email: rahmanif@tbzmed.ac.ir \\ Competing interests: None. \\ Funding information: None. \\ Citation: Ala A, Rahmani F, Aslzad \\ $R$, Parsian Z. The effect of training \\ on the management of nuclear \\ disasters by emergency department \\ nurses and physicians. Journal of \\ Emergency Practice and Trauma \\ 2018; 4(1): 14-17. doi: 10.15171/ \\ jept.2017.20
}

\begin{abstract}
Objective: On account of the widespread use of nuclear energy in different fields, nuclear accidents and disasters have been on a rise. Thus, it is crucial for medical staff especially emergency department personnel to be aware of the nature of these accidents. This study was designed to evaluate the effect of training on the knowledge of physicians and nurses regarding nuclear disasters.

Methods: This pre-and post-intervention study was conducted on 97 emergency department personnel including physicians and nurses of educational hospitals in Tabriz University of Medical Sciences. Educational classes and training about nuclear disasters and managing these events were held. A standard questionnaire was used to evaluate the knowledge before and after training, and the effect of education on personnel's knowledge.

Results: Our participants included 41 males and 56 females. The mean age was 32.88 years. The mean score of participants before and after the class was $4.03 \pm 1.54$ and $7.93 \pm 1.55$ respectively; which showed a statistically significant difference $(P<0.001)$. Among medical staff, physicians had better knowledge compared with the other group.

Conclusion: This study showed that the knowledge of medical staff about nuclear disasters is low and educational classes are necessary to increase their knowledge.

Keywords: Disasters, Nuclear accidents, Education, Emergency service, Hospital
\end{abstract}

\section{Introduction}

Nowadays nuclear energy and nuclear products are utilized in medicine, industry, agriculture and research. In spite of security measures and regarding international standards, 405 nuclear accidents occurred from 1994 to 1999 (1). Lack of trained and experienced staff to face and control side effects of such accidents increases the victims and mortality rate. For this purpose, International Nuclear Agency has requested the countries with nuclear technology to consider requisite training in this field (2). Wherever nuclear accidents take place, the existence of trained personnel and medical staff at the scene is necessary, and saving victims' lives and resuscitation are more important than decontamination $(3,4)$. As a large number of people are affected by the radioactive material and radiation of these accidents in urban areas, this poses a huge burden on medical systems. If we are not prepared for facing these accidents, not only disaster management will fail and cause anxiety and stress for people and medical personnel but also it will culminate in impaired treatment of victims. Moreover, it will provide a worse socio-psychological disaster (5).
Most of the victims of nuclear accidents are not aware of their exposure to radiation. Unawareness of drawbacks of accidental exposure to nuclear radiation is one of the most important reasons of delayed diagnosis of radiation associated injuries. As a consequence they are not treated effectively. Surveys about worldwide nuclear accidents show that the majority of general physicians and medical staff do not have the necessary information about the effects of ionized radiation and the required treatment and management of victims of nuclear disaster $(6,7)$. A study showed that physicians apart from radiologists are unaware of the benefits of protection against radiation and biology of radiation (8). Human society has learned a lot from previous nuclear disasters in the world and with the experiences of these events primary medical response to the victims of nuclear accidents is defined. International nuclear energy agency has offered a protocol for the treatment and diagnosis of nuclear victims (safety report series N2, 1998); which is very helpful for the physicians who are responsible for the treatment of nuclear victims in nuclear disasters (1).

On the other hand, development of our country, Iran, in 
nuclear energy signifies the importance of awareness for medical staff including managers, physicians and nurses from international patterns and principles regarding nuclear disasters. A study conducted by Tavakoli et al (9) demonstrated that among 137 staff of Baqiyatallah University of Medical Sciences, including managers, physicians and nurses the majority of participants had acceptable information about the right method of managing and treating nuclear disasters. Another study performed by Hosseini et al (10) in Isfahan University of Medical Sciences among nurses and attending physicians showed that half of the participants had enough information about nuclear accidents models. Therefore, researchers emphasized on the necessity of these courses as a part of a nursing student schedule and planning for continued training of nurses.

Taking into account the difference in knowledge and human resources, equipment and facilities of each region, evaluating the knowledge of medical staff about managing victims of nuclear disasters has significant importance. So, this study aimed to evaluate the effect of education on the knowledge of managing victims of nuclear disaster by emergency physicians and nurses in order to improve the level of their knowledge by educational recommendations.

\section{Methods}

This pre-post intervention study was conducted in the emergency departments of Tabriz University of Medical Sciences. Participants included all residents and medical staff of emergency departments of Imam Reza, Sina, and Taleghani hospitals of Tabriz University of Medical Sciences. Exclusion criteria included (a) lack of participation in the study and $(b)$ failing to attend either pretest or posttest or both of them. Written consent that explained the circumstance of the study was obtained.

The questionnaire consisted of 2 parts. The first part encompassed the demographic information of participants and the second part consisted of 15 multiple choice questions about nuclear events and their management. Five questions were designed as interval scale questions regarding personnel's knowledge of nuclear accidents. Participants were asked to answer the questions as: I do not have any information, I have general information, I have little specialized information, and I have enough information. The information was analyzed according to the answers.

The remaining 10 questions were specific multiple choice questions with one correct answer. Reliability of the questionnaire was obtained by content validity and construct validity. In this regard, attending physicians of emergency medicine of Tabriz University of Medical Sciences were asked to provide their comments on the questionnaire. The validity was evaluated by Cronbach $\alpha$ and Cronbach $a$ of 80.0 was obtained which is acceptable. After explaining the objective of the study, clarifying any matters regarding the questionnaire and obtaining participants' consent, pretest was performed. After taking the pretest, an educational class about radiation, its side effects and the appropriate management of nuclear accidents was held (11). Training was face to face with group discussion for 2 hours. The lecture was performed by an attending physician of scientific committee of the university. Finally, posttest was taken with the same questions 2 hours after the class.

In order to analyze data descriptive statistical methods (frequency, percent, mean, and standard deviation) were used. Normal distribution of the data was confirmed using Kolmogorov-Smirnov test. In order to compare qualitative and quantitative data, $\chi^{2}$ test, and paired $t$ test were used consecutively. $P$ value less than 0.05 was considered significant. Data were analyzed using SPSS software version 17 .

\section{Results}

Totally 97 participants ( 41 males and 56 females) took part in the study. The mean age of participants was $32.88 \pm 6.67$ years. Concerning marital status, 30 (30.6\%) were single and 67 (69.1\%) were married. In terms of participants' job, 33 of them were emergency medicine residents and $67 \%$ were nurses. The information was gathered from three main hospitals of Tabriz University of Medical Sciences. $13.5 \%, 34.4 \%$ and $62 \%$ of participants were from Imam Reza, Taleghani and Sina hospital respectively. Table 1 shows the medical personnel's knowledge about nuclear events before and after training (questions 1, 2, 10, 11, and 16). Question 1 was about their knowledge regarding the side effects of nuclear accidents, question 2 was about their knowledge regarding radiation monitoring equipment, question 10 was about their familiarity with radioactive products and decontamination methods, question 11 was about knowing how to protect themselves during a nuclear accident and question 16 was about the familiarity with reporting protocols of nuclear accidents.

For the remaining 10 multiple choice questions, the average of participants' score was $4.03 \pm 1.54$ and $7.93 \pm 1.55$ before and after training respectively which showed a meaningful difference between the results before and after training $(P$ $<0.001$ ).

Table 2 demonstrates the results for 2 groups of nurses and physicians. As shown in Table 2, there was a significant statistical difference between the groups before and after training $(P<0.001)$. There was also a significant difference between the scores of 2 groups before training $(P<0.001)$, but after education the difference was not statistically significant $(P=0.051)$. The difference in pretest results might have ensued from encompassing nuclear accidents in the references of emergency medicine.

With regard to the open question about the necessity of opening a special ward for nuclear accidents victims in the hospital, the results are shown in Table 3. Comparing the answers of physicians and nurses before and after training showed not meaningful difference before training $(P=0.686)$ but there was a meaningful difference after training $(P<0.001)$. The answer of many physicians for opening such a ward was very necessary $(68.8 \%$ versus $26.2 \%)$. 
Table 1. Evaluation of medical personnel's knowledge about nuclear events before and after training

\begin{tabular}{|c|c|c|c|c|c|c|c|}
\hline \multirow[b]{2}{*}{ Group } & \multirow[b]{2}{*}{ Question } & & \multicolumn{4}{|c|}{ Answer } & \multirow[b]{2}{*}{ P value } \\
\hline & & & $\begin{array}{c}\text { Without } \\
\text { Information }\end{array}$ & $\begin{array}{c}\text { Some } \\
\text { Information }\end{array}$ & $\begin{array}{c}\text { Some specialized } \\
\text { Information }\end{array}$ & $\begin{array}{c}\text { Enough } \\
\text { Information }\end{array}$ & \\
\hline \multirow{10}{*}{ Physicians } & \multirow{2}{*}{ Q1 } & Pretest & $3(9.4 \%)$ & $21(65.6 \%)$ & $7(21.9 \%)$ & $1(3.1 \%)$ & \multirow{2}{*}{0.323} \\
\hline & & Posttest & $3(9.4 \%)$ & $16(50.0 \%)$ & $0(0.0 \%)$ & $13(40.6 \%)$ & \\
\hline & \multirow{2}{*}{ Q2 } & Pretest & 27 (84.4\%) & $5(15.6 \%)$ & $0(0.0 \%)$ & $0(0.0 \%)$ & \multirow{2}{*}{0.034} \\
\hline & & Posttest & 1 (3.1\%) & $17(53.1 \%)$ & $1(3.1 \%)$ & $13(40.6 \%)$ & \\
\hline & \multirow{2}{*}{ Q10 } & Pretest & $9(28.1 \%)$ & $18(56.3 \%)$ & $5(15.6 \%)$ & $0(0.0 \%)$ & \multirow{2}{*}{0.198} \\
\hline & & Posttest & $6(18.8 \%)$ & $0(0.0 \%)$ & $20(62.5 \%)$ & $6(18.8 \%)$ & \\
\hline & \multirow{2}{*}{ Q11 } & Pretest & 6 (18.8\%) & 20 (62.5\%) & $6(18.8 \%)$ & $0(0.0 \%)$ & \multirow{2}{*}{0.098} \\
\hline & & Posttest & $8(25.0 \%)$ & $0(0.0 \%)$ & 18 (56.3\%) & $6(18.8 \%)$ & \\
\hline & \multirow{2}{*}{ Q16 } & Pretest & $18(56.3 \%)$ & 12 (37.5\%) & $2(6.3 \%)$ & $0(0.0 \%)$ & \multirow{2}{*}{0.194} \\
\hline & & Posttest & $6(18.8 \%)$ & $6(18.8 \%)$ & $16(50.0 \%)$ & $4(12.5 \%)$ & \\
\hline \multirow{10}{*}{ Nurses } & \multirow{2}{*}{ Q1 } & Pretest & 31 (47.7\%) & 30 (46.2\%) & $3(4.6 \%)$ & $1(1.5 \%)$ & \multirow{2}{*}{0.718} \\
\hline & & Posttest & $2(3.1 \%)$ & $26(40.0 \%)$ & $17(26.2 \%)$ & 20 (30.8\%) & \\
\hline & \multirow{2}{*}{ Q2 } & Pretest & 52 (80.0\%) & 12 (18.5\%) & $0(0.0 \%)$ & 1 (1.5\%) & \multirow{2}{*}{0.621} \\
\hline & & Posttest & $8(12.3 \%)$ & $31(47.7 \%)$ & $0(0.0 \%)$ & $26(40.0 \%)$ & \\
\hline & \multirow{2}{*}{ Q10 } & Pretest & 33 (50.8\%) & 29 (44.6\%) & $3(4.6 \%)$ & $0(0.0 \%)$ & \multirow{2}{*}{0.841} \\
\hline & & Posttest & $13(20.0 \%)$ & $0(0.0 \%)$ & 50 (76.9\%) & $2(3.1 \%)$ & \\
\hline & \multirow{2}{*}{ Q11 } & Pretest & $28(43.1 \%)$ & 34 (52.3\%) & $3(4.6 \%)$ & $0(0.0 \%)$ & \multirow{2}{*}{0.020} \\
\hline & & Posttest & 14 (21.5\%) & $0(0.0 \%)$ & 48 (73.8\%) & $3(4.6 \%)$ & \\
\hline & \multirow[b]{2}{*}{ Q16 } & Pretest & 46 (70.8\%) & 17 (26.2\%) & 2 (3.1\%) & $0(0.0 \%)$ & \multirow{2}{*}{0.529} \\
\hline & & Posttest & $2(3.1 \%)$ & $16(24.6 \%)$ & 46 (70.8\%) & $1(1.5 \%)$ & \\
\hline
\end{tabular}

\section{Discussion}

In this study the knowledge of physicians and nurses about encountering and managing nuclear disasters were evaluated and assessed. The average of scores participants was $4.03 \pm 1.54$ and $7.93 \pm 1.55$ before and after training respectively which showed a meaningful difference between the results before and after training $(P<0.001)$. There was also a significant difference between the scores of 2 groups before training, but after education the difference was not statistically significant. Schleipman et al (12) evaluated the approach to 21 patients with suspected exposure to nuclear radiation during a period of 2 hours in the emergency department simulation. Eleven persons were assumed unaffected and 10 were assumed affected to evaluate the method of approach, management, diagnosis and treatment. It was demonstrated that in spite of controlled treatment, lack of appropriate algorithm for managing and facing these crises, usual approaches will

Table 2. Results of participants in 2 groups: nurses and physicians

\begin{tabular}{llll}
\hline & Pre-test score & Post-test score & P value \\
\hline Physicians & $5.31 \pm 1.23$ & $7.50 \pm 1.90$ & $<0.001$ \\
Nurses & $3.40 \pm 1.27$ & $8.15 \pm 1.31$ & $<0.001$ \\
P value & $<0.001$ & 0.051 & \\
\hline
\end{tabular}

not be as effective as before. Studies in our country also show the need for educational classes in order to improve the knowledge of medical staff $(9,10)$.

Considering the researches in this area and the existence of different models for managing victims of nuclear events and disasters, the need for new models in order to manage these crises is crucial. Jaques (13) made amendments to the limitation of previous models and presented a relatively complete model. Due to the importance of this subject, management models in disasters are included in recently written books for general disaster management $(14,15)$.

Taking the previous nuclear disasters of the whole world into account it becomes clear that medical staff do not have enough information to face these events $(10,15)$. The results of our study showed that simple education can increase safety level of medical staff and patients against ionizing radiation. As in our study, a simple educational class elevated the knowledge of medical staff. In our study, the results of questions about the way of decontamination in hospital environment, the way of protection against ionizing radiation, the way to decrease radiation exposure showed that only $30 \%$ of all participants answered the questions correctly. By conducting appropriate training for medical staff, desirable level of knowledge for managing

Table 3. Opinions of participants about necessity of opening a special ward for nuclear accidents victims in the hospital

\begin{tabular}{llcccc}
\hline & Stage & Low necessity & Necessary & Very necessary & P value \\
\hline \multirow{2}{*}{ Physicians } & Pre-test & $5(15.6 \%)$ & $18(56.3 \%)$ & $9(28.1 \%)$ & 0.351 \\
& Post-test & $2(6.3 \%)$ & $8(25.0 \%)$ & $22(68.8 \%)$ & $16(24.6 \%)$ \\
\multirow{2}{*}{ Nurses } & Pre-test & $7(10.8 \%)$ & $42(64.4 \%)$ & $17(26.2 \%)$ & 0.131 \\
& Post-test & $4(6.2 \%)$ & $44(67.7 \%)$ & & \\
\hline
\end{tabular}


nuclear crises can be reached. The problem is that this process is time consuming and costly, and good level of knowledge does not necessarily mean good reaction in nuclear crises. For reaching good levels of reaction to nuclear disasters variety of theoretical and practical trainings are needed (16).

One of the interesting results of our study was the difference between the answers of physicians and nurses to the question about the necessity of opening a special ward for taking care of nuclear crises victims, that was higher among physicians compared with nurses.

\section{Conclusion}

Considering the results of the present study and the fact that nuclear disasters are unpredictable and life threatening, it is recommended to train medical staff of the emergency department. One of the most effective ways is to conduct educational work-shops in order to recognize and manage nuclear accidents. The problems of managing nuclear accidents can be shown better while performing preparation maneuvers. Additionally, owing to the importance of nuclear disasters management, it is recommended to references about managing nuclear accidents is included in the schedule of nurses and physicians.

\section{Limitations of study}

Inability to take posttest exam after a longer period of time and evaluating the consistency of training were the limitations of our study.

\section{Acknowledgments}

The authors are grateful to all the health personnel and patients who participated in the study. This article was written based on a dataset of MD thesis, registered in Tabriz University of Medical Sciences [Number: 94/39/11, Approved date: 11.08.2015].

\section{Ethical issues}

The current study was confirmed by the Ethics committee of Tabriz University of Medical Sciences with code number 12426 in 25.01.2016. Informed consent was taken from the participants for the study.

\section{Authors' contributions}

All authors have read and approved the manuscript. FR and RA performed the data collection, writing, critical revision and drafting of the manuscript. $\mathrm{AA}$ and $\mathrm{ZP}$ undertook the major parts of the study design and performed the statistical analysis, data analysis and data interpretation.

\section{References}

1. IAEA. Diagnosis and Treatment of Radiation Injuries,
Safety Reports Series No. 2. Vienna: IAEA; 1998. p. 49.

2. Monfared AS. Nuclear weapons, triage of injured and therapeutic approach to the acute radiation syndrome. Annals of Military and Health Sciences Research 2004; 2(4): 463-6. [In Persian].

3. Ghobeishavi V, Forughizadeh M. External decontamination in nuclear accidents. Journal of Military Medicine 2003; 5(1): 57-68. [In Persian].

4. Moroni M, Elliott TB, Deutz NE, Olsen CH, Owens R, Christensen $\mathrm{C}$, et al. Accelerated hematopoietic syndrome after radiation doses bridging hematopoietic (H-ARS) and gastrointestinal (GI-ARS) acute radiation syndrome: Early hematological changes and systemic inflammatory response syndrome in minipig. Int J Radiat Biol 2014; 90(5): 363-72. doi: 10.3109/09553002.2014.892226.

5. Poorheidari G, Najafi A, Khatami M, Modares MS. How to prepare a general hospital emergency ward to admit nuclear casualties. Kowsar Medical Journal 2003; 7(4): 333-9. [In Persian].

6. Meineke V, van Beuningen D, Sohns T, Fliedner TM. Medical management principles for radiation accidents. Mil Med 2003; 168(3): 219-22.

7. Turai I, Veress K, Gunalp B, Souchkevitch G. Medical response to radiation incidents and radionuclear threats. BMJ 2004; 328(7439): 568-72. doi: 10.1136/ bmj.328.7439.568.

8. Quinn A, Taylor C, Sabharwal T, Sikdar T. Radiation protection awareness in non-radiologists. Br J Radiol 1997; 70(829): 102-6. doi: 10.1259/bjr.70.829.9059306.

9. Tavakoli H, Modarresi SM, Azad Marzabadi E. Educational needs of hospital personnel for medical response to nuclear injuries. Journal of Military Medicine 2008; 10(3): 209-16. [In Persian].

10. Hoseini A, Musarezaie A, Eslamian J. Awareness of radiological accidents and how to deal with it: a study of nurses and nursing faculties of Isfahan University of Medical Sciences. Iranian Journal of Medical Education 2014; 14(1): 78-86. [In Persian].

11. Lopez AM, Stephani JA. Radiation injuries. In: Tintinalli JE, Stapczynski JS, Ma OJ, Cline DM, Cydulka RK, Meckler GD, et al, eds. Tintinalli’s Emergency Medicine: A Comprehensive Study Guide. 8th ed. USA: McGraw Hill; 2016. p. 51-7.

12. Schleipman AR, Gerbaudo VH, Castronovo FP. Radiation disaster response: preparation and simulation experience at an academic medical center. J Nucl Med Technol 2004; 32(1): 22-7.

13. Jaques T. Issue management and crisis management: an integrated, non-linear, relational construct. Public Relat Rev 2007; 33(2): 147-57. doi: 10.1016/j.pubrev.2007.02.001.

14. Drennan LT, McConnell A. Managing the acute phase of crisis. In: Drennan LT, McConnell A, et al. Risk and Crisis Management in the Public Sector. New York: Routledge; 2007. p. 145-74.

15. Mettle FA Jr, Voelz GL. Major radiation exposure-What to expect and how to respond. N Eng J Med 2002; 346(20): 1554-61. doi: 10.1056/NEJMra000365.

16. Farazmand A. Handbook of Crisis and Emergency Management. USA: Marcel Dekker; 2001. 